\title{
Intracerebral Hemorrhage in Pointe a Pitre Hospital
}

\author{
Mendinatou Agbetou ${ }^{1,2 *}$, Thierry Adoukonou ${ }^{2}$, Cosmin Alecu ${ }^{1}$, Anne Landais ${ }^{1}$, Annie Lannuzel ${ }^{1}$ \\ ${ }^{1}$ Service de Neurologie du CHU Pointe-à-Pitre, Université Antilles-Guyane, Pointe-à-Pitre, France \\ ${ }^{2}$ Unité d'Enseignement et de Recherche de Neurologie, Université de Parakou, Parakou, Bénin \\ Email: *mendiagbetou@yahoo.fr
}

How to cite this paper: Agbetou, M. Adoukonou, T., Alecu, C., Landais, A. and Lannuzel, A. (2018) Intracerebral Hemorrhage in P. World Journal of Neuroscience, 8, 403-410. https://doi.org/10.4236/wjns.2018.84031

Received: August 25, 2018

Accepted: September 27, 2018

Published: September 30, 2018

Copyright (c) 2018 by authors and Scientific Research Publishing Inc. This work is licensed under the Creative Commons Attribution International License (CC BY 4.0).

http://creativecommons.org/licenses/by/4.0/

(c) (i) Open Access

\begin{abstract}
Background: In caribbean space stroke incidence is $50 \%$ higher than in Europe. This study aims to describe characteristics of intracerebral hemorrhage in Guadeloupe. Methods: This was a retrospective study of hospitalized patients with a no-traumatic intracerebral hemorrhage during one year from 2013 to 2014. Survivors were contacted by telephone at the end of the study and; if accept, vital status and Rankin scale were assessed. Results: In one year, 1418 patients were hospitalized for an acute stroke. 112 had no-traumatic intracerebral hemorrhage (7.9\%). The sex ratio $\mathrm{F} / \mathrm{H}$ was 0.72 . Mean age of the population was at $63.0 \pm 14.7$ years. Hypertension and diabetes were the leading risk factors notice with respectively 62 and 25 patients. Intracerebral hemorrhage distribution was: deep $48.2 \%$, lobar $30.4 \%$, sub-tentorial $17.9 \%$, meningeal $3.5 \%$. Severity signs distribution were mass effect $79 \%$, ventricular contamination $43 \%$ and cerebral herniation $37 \%$. Mean during of in-hospital stay was $10.6 \pm 10.3$ days and in-hospital mortality was 22 patients (19.6\%). A year and a half after emergency 5 additional death (4.5\%) between 35 patients survivors was noticed with median Rankin scale 1.5. Conclusion: Intracerebral hemorrhage is less frequent in African American as compared to Caucasian; the epidemiological excess of strokes in this population is related to ischemic strokes.
\end{abstract}

\section{Keywords}

Stroke, Intracerebral Hemorrhage, Guadeloupe

\section{Introduction}

The burden of intra-cerebral hemorrhages (ICH) varies between regions and over time. Their incidence seems be influenced by ethnicity and is dependent of socio-economic conditions. Krishnamurthi in a meta-analysis including world- 
wide studies found $80 \%$ of incident cerebral hematoma in low-income and middle-income countries. Worldwide, their burden increased by $47 \%$ between 1990 and 2010 [1].

Several studies demonstrated higher stroke incidence and mortality in US and UK Blacks than in Caucasians [2] [3] [4] [5]. Therefore, stroke appears as a major public health problem in terms of morbidity and mortality in black populations outside the United States and United Kingdom too, especially in Caribbean [6].

Epidemiological data on stroke in African Caribbeans are comparable to those reported in blacks from the United States and United Kingdom [2].

In Martinique and Guadeloupe (French West Indies FWI), stroke population studies showed a high prevalence of hypertension and diabetes compared with those observed in continental France [6] [7]. Nevertheless, the Caribbean stroke population studies showed lower rapport cerebral hematoma/ischemic strokes than in European populations (17.7\% [6]) suggesting that the high incidence of strokes in this population can be related mainly to a higher incidence of ischemic strokes. Considering the high incidence of hypertension and diabetes, a higher incidence of deep hematoma would be expected. The aim of our study was to indicate the cerebral hematoma incidence in stroke patients hospitalized in Guadeloupe and to characterize the hematoma types and prognostic in these patients.

\section{Methods}

We performed a retrospective study of all hospitalized patients who presented a no-traumatic ICH during two years in the University Hospital Guadeloupe.

Guadeloupe (FWI) is an archipelago composed by two main islands (Grande Terre and Basse Terre) and six other islands distant from 14 to $250 \mathrm{~km}$ from the central Islands with a total population of 402,119 in 2013. The data of regional health agency indicates 1034 hospitalizations for stroke in 2014 in the entire archipelago.

University Hospital of Pointe a Pitre has 862 beds and makes 69906 emergency admissions at the end of 2010. University hospital has the rule of local hospital for Grande Terre Island and tertiary center for the entire archipelago. Grande Terre Island is the 25th urbanagglomeration of France by its population; 257.361 inhabitantsin 2012, 63.8\% of the population of Guadeloupe, with averagedensity 353 people per $\mathrm{km}^{2}$. Here is situated the only Stroke Unit of the archipelago. Therefore 742/1034 of stroke hospitalizations of all archipelago held in the University Hospital, the majority in the Stroke Unit.

Selection method: Cases were selected in the informatics system of the University Hospital, using related International Classified Diseases (ICD) items after a systematic search of all hospitalized patients during two years (2013-2014). The diagnosis of stroke of all selected cases was validated by two Neurologists (MA, CA) using the Emergency Department informatics system and Web PACS 
DIAM4 2.5 software, Global Imaging Online 97,100 Montreuil France.

Intra-cerebral hemorrhage (ICH) was defined by presence of blood in cerebral parenchyma or some meningeal spaces (sub-tentorial or sub arachnoid or ventricular (excluding post traumatic hematoma) or both of them.

Hypertension was defined as systolic blood pressure (SBP) $\geq 140 \mathrm{mmHg}$ or self-reported use of antihypertensives medications.

Diabetes was defined as fasting glucose $\geq 1.26 \mathrm{~g} / \mathrm{L}$ twice or once $\geq 2 \mathrm{~g} / \mathrm{L}$ or self-reported use of diabetic medication.

The National Institute of Health Stroke Scale (NIHSS) range from 0 (normal neurologic status) to 42 (coma with quadriplegia) was used to evaluate patients in acute phase of stroke. The level of consciousness, eye-motor skills, vision, facial palsy, movement of limbs, ataxia members, sensitivity, language, dysarthria, extinction and neglect were quotes [8].

The scores on the Glasgow Coma Scale (GCS) range from 15 (fullyconscious) to 3 (deep coma).

The modified Rankin Scale (mRS) is a functional assessment scale after stroke side 0 to 6 . Patients have no symptoms at all at 0 . He was listed 1 if no significant disability despite symptoms, and able to carry out all usual duties and activities; 2 if slight disability existed and unable to carry out all previous activities, but was able to look after own affairs without assistance. He was listed 3 if moderate disability, requiring some help but patient was able to walk without assistance; 4 if there has moderetly severe disability, patient was unable to walk without assistance and was unable to attend to own bodily needs without assistance. 5 if there had severe disability, bedridden, incontinent and required constant nursing care and attention. 6 if the patient was dead [9] [10].

Leukoaraiosis was classified by the score of FAZEKAS. 0 if no periventricular lesion, 1 if punctate or fine lines periventricular lesion, 2 if it's in halo, 3 if periventricular lesion was extensive in the white matter [11]. About the lesions of the deep white matter 0 if there were no lesion, 1 if lesions were punctate, 2 if confluence debutante and 3 if there were multiple confluent areas.

Exclusion criteria: After validation, we excluded cases of post-traumatic hematoma and patients with hemorrhagic infarction.

Survivors were contacted by telephone at the end of the study and, if accepted, vital status and Modified Rankin Scale (MRS) were assessed.

Statistical method: Data were analysed with IBM-SPSS (IBM, Armonk, NY, USA). The quantitative variables were expressed in averages with their standard deviation, categorial variables where expressed in proportion with their confidence interval at $95 \%$. The proportions were compared with the test of chi-square $\left(\mathrm{Khi}^{2}\right)$ or exact test of Fischer. Statistical significance was set at $5 \%$.

Authorization from the hospital authorities was obtained before the study.

\section{Results}

Between 1418 patients hospitalized for an acute stroke 112 had no-traumatic $\mathrm{ICH}(7.9 \%)$. The sex ratio $\mathrm{F} / \mathrm{H}$ was 0.72 . Mean age of the population was at 63.0 
\pm 14.7 years. The average NIHSS ranged from 10 to 14 among men and women. Mean Systolic blood pressure was at $166.1 \mathrm{mmHg}$. A past history of HTA was noticed in $55.4 \%$ of patients and most of them were treated with an average of 1.2 antihypertensive drugs with a max of 4 treatments (two patients) and minimum no treatment. Five patients had three antihypertensive drugs as treatment. The clinical characteristics of this population are summarized in Table 1.

At the admission, 41 patients $(36.3 \%)$ had no consciousness trouble and 11 patients $(9.8 \%)$ had indication of intubation.

The mean value of temperature was $36.8^{\circ} \mathrm{C} \pm 0.8^{\circ} \mathrm{C}$, and mean blood glucose level was $1.6 \pm 0.7 \mathrm{~g} / \mathrm{l}$.

Pulse pressure values were not correlated with haematoma sub-types or gender, but only with age such as indicated in Figure 1.

Hypertension and diabetes were the leading risk factors notice with respectively 62 and 25 patients. In this series no patient had a treatment by new oral anticoagulant. Thrombotic treatment was noticed with 20 patients, alcohol consumption in 9 patients and hyperlipidemia with statins therapy in 14 patients. Table 2 resumes the main risk factors.

Clinically the most frequent symptoms were: hemi-paresis 58.9\% (66 patients), aphasia $37.5 \%$ (42 patients), loss of consciousness $32.1 \%$ (36 patients) and headache $19.6 \%$ (22 patients).

About biologicalabnomalities, 13 patients (11.6\%) have thrombocytes count lower than $150 \mathrm{G} / \mathrm{l}$. Mean thromboplasmin was 88.1\% [25\% - 113\%] and meanactivated partial thromboplasmin time 1.1 [0.62 - 1.59]. Only one patient had TCA greater than 1.5. The International Normalized Ratio (INR) was greater than 1.5 in 7 patients. Only two patient had INR greater than 2, no more patient had INR greater than 3 .

ICH topography was deep in $48.2 \%$ of cases and lobar in $30.4 \%$ with mass

Table 1. Clinical characteristics of the population.

\begin{tabular}{|c|c|c|c|c|}
\hline & Men & Women & Total & $\mathrm{p}$ \\
\hline Number & 65 & 47 & 112 & NS \\
\hline Age (years, mean, SD) & $60.8 \pm 13.1$ & $66.1 \pm 16.2$ & $63.0 \pm 14.7$ & 0.05 \\
\hline NIHSS (mean, SD) & $10.8 \pm 7.8$ & $14.3 \pm 10.0$ & $11.5 \pm 8.2$ & $<0.05$ \\
\hline GCS (mean, SD) & $13.2 \pm 3.0$ & $11.5 \pm 3.4$ & $12.4 \pm 3.3$ & 0.06 \\
\hline Past history of HTA $(\%, C I)$ & $53.8[41.7-6.0]$ & $57.4[43.3-71.6]$ & $55.4[46.2-64.6]$ & NS \\
\hline $\begin{array}{l}\text { Number of antihypertensive } \\
\text { agents ( } 0 \text { to } 4) \text { (mean, SD) }\end{array}$ & $0.9 \pm 1.2$ & $1.6 \pm 1.0$ & $1.2 \pm 1.2$ & $<0.01$ \\
\hline SBP (mmHg, mean, SD) & $166.2 \pm 39.6$ & $165.9 \pm 29.2$ & $166.1 \pm 34.9$ & NS \\
\hline PAM (mmHg, mean, SD) & $120.2 \pm 28.1$ & $117.1 \pm 20.1$ & $118.8 \pm 24.5$ & NS \\
\hline PP (mmHg, mean, SD) & $67.5 \pm 25.6$ & $73.2 \pm 21.9$ & $70.2 \pm 23.9$ & NS \\
\hline
\end{tabular}

NS = No Significance; SD = Standard Deviation; $\%=$ Percentage; $\mathrm{CI}=$ Confidence Interval; $\mathrm{mmHg}=\mathrm{Mil}-$ limeter of Mercury; SBP = Systolic Blood Pressure; PAM = Mean Arterial Pressure; PP = Pulse Pressure. 
Table 2. Percentage of patient with one or more risk factor.

\begin{tabular}{lcc}
\hline Risk factor & Total & Percentage (\%) \\
\hline HTA & 62 & 55.4 \\
Diabetes & 25 & 22.3 \\
Stroke subtype & 15 & 13.4 \\
$\checkmark$ hemorrhage & 6 & 5.4 \\
$\checkmark$ ischemic & 9 & 8 \\
Thrombotictreatment & 20 & 17.9 \\
$\checkmark$ antiplatelet & 14 & 12.5 \\
$\checkmark$ antivitamine K & 5 & 4.5 \\
$\checkmark$ heparin & 1 & 0.9 \\
$\checkmark$ new anticoagulant & 0 & 0 \\
Statinstherapy & 14 & 12.5 \\
Alcohol & 9 & 8 \\
\hline
\end{tabular}

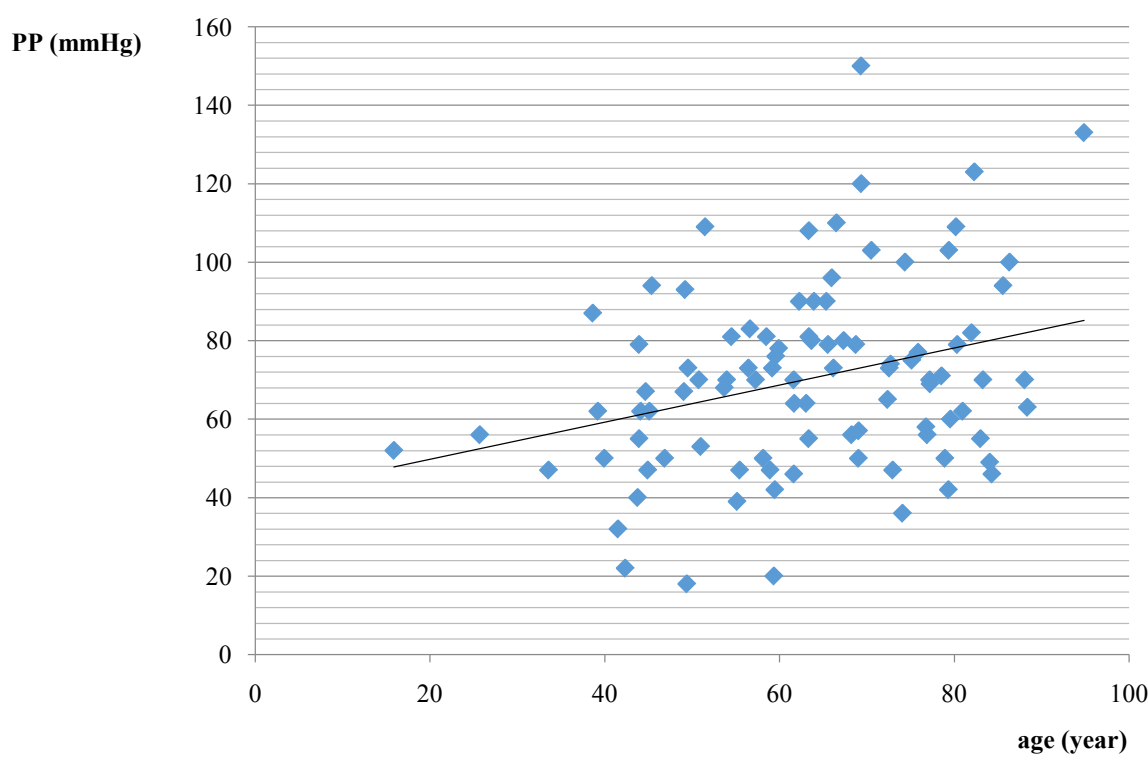

Figure 1. Correlation between pulse pressure and age of patients.

effect in $79.5 \%$. Microbleeds existed in 16 patients and leukoencephalopathy stage 3 in 50 patients. Vascular imagery aspects were reported in Table 3.

\section{Discussion}

This series is representative for the Guadeloupian strokes population, since a great majority of stroke patients are admitted in the hospital where the study was performed. The limitations of the study are constituted by its retrospective design and by the important fraction of lost of follow-up who limit ours results concerning the long term mortality and functional prognosis.

In this study involving patients with intracerebral hemorrhage, the mean age at 63 years, male predominance, the high values of systolic blood pressure and $\mathrm{NIH}$ are similar to another populations such as in the northen America's study 
Table 3. Results of brainimaging in patients.

\begin{tabular}{lcc}
\hline Imaging aspects & Total & Percentage \\
\hline ICH topography & 54 & \\
$\checkmark$ deep & 20 & $48.2 \%$ \\
$\checkmark$ sub-tentorial & 34 & $30.4 \%$ \\
$\checkmark$ lobar & 4 & $3.6 \%$ \\
$\checkmark$ meningeal & & \\
Severity signs distribution & 48 & $42.9 \%$ \\
$\checkmark$ ventricular contamination & 89 & $79.5 \%$ \\
$\checkmark$ mass effect & 41 & $36.6 \%$ \\
$\checkmark$ cerebral herniation & 37 & $33.1 \%$ \\
$\checkmark$ sub-arachnoid contamination & 16 & $14.3 \%$ \\
$\checkmark$ microbleeds & & \\
Etiology funded & 7 & $6.3 \%$ \\
$\checkmark$ aneurysm & 8 & $7.1 \%$ \\
$\checkmark$ arterio-venous malformation & & \\
Leukoencephalopathy & 50 & $44.6 \%$ \\
$\checkmark$ stage 3 & 23 & $20.5 \%$ \\
$\checkmark$ stage 2 & 0 & $0 \%$ \\
$\checkmark$ stage 1 & 27 & $24.1 \%$ \\
$\checkmark$ stage 0 & & \\
\hline
\end{tabular}

Interact $2(63.0 \pm 13.1,64.2 \%$ of men, PAS $179 \pm 17 \mathrm{mmHg}$, NIHSS 10) [12]. In Ermancia study in Martinique, they were more women $50.9 \%$ and mean age of the population was superior to our (71.214 years) [6]. Women tend to be older than men $(66.1$ vs 60.8 years $\mathrm{p}=0.05)$ suggesting that women have a longer life expectancy than men; and they have more severe stroke $(\mathrm{p}=0.04)$. These characteristics were found also in Interact 2 and Ermancia studies related to the size and severity of hypertension in women in all this studies.

Hematoma was deep like in Interact study (83.8\%) but our patients present more severe sign at the imaging, ventricular contamination ( $43 \%$ vs $28.7 \%$ ). This localization is also in favor of hypertensive origin of intracerebral hemorrhage.

In thisserie, few patients had an tithrombotique overdose even if theywere more patient than in interact studie using antiplatelet or antivitamin $\mathrm{K}(12.5 \% \mathrm{vs}$ $8.8 \%$ and $4.5 \%$ vs $3.6 \%$ ).

But past history of hypertension is lower (55.4\%) compared to another studies 69.1\% in ERMANCIA, $72.4 \%$ in Interact 2.

In one of the very few prospective examinations of risk factors for $\mathrm{ICH}$, Sturgeon and colleagues reported that older age, black race, and hypertension were risk factors for incident ICH [13].

The during of intra-hospital staying is lower in our study compared to the during in Interact 2 study (20 days) probably due to limited place face to high admission demand in the unit.

The Guadeloupean population is engaging in a rapid westernization of lifestyle and could be in a position to increase the magnitude of the stroke burden. But in this study, strokes proportion is in down, from $10 \%$ for the hemorrhagic stroke in 1999 [14] to $7.9 \%$ in this study. At the same way, in Dijon's register, 
despite the increase in the risk factor in the population, stroke incidence rates have not increased [5].

Mortality is high in acute state in this study (19.6\% vs $11.9 \%$ in Interact 2 ) probably because of small sample size, and linked to a high prevalence of hypertension. Thus, stroke is a significant contributor to higher overall mortality in African American's populations.

More than one third of patients presents initial very severe state especially among women, but the functional prognosis is less severe regarding the mean Rankin scale 1.5 at distance from the event. Post haemorrhagic stroke dependance is variously estimated. One year after a first stroke, the level of dependance in an intrahopital study in Guadeloupe was stable and quality of life altered, despite a significant improvement of neurological handicap [7].

\section{Conclusion}

The percent of intracerebral hemorrhage between strokes is lower, suggesting that the stroke excess in Caribbean is mainly related to the ischemic strokes. Women are older and have more severe stroke and in this series there are no anticoagulant overdose.

\section{Conflicts of Interest}

The authors declare no conflicts of interest regarding the publication of this paper.

\section{References}

[1] Krishnamurthi, R.V., Moran, A.E., Forouzanfar, M.H., Bennett, D.A., Mensah, G.A., Lawes, C.M., Barker-Collo, S., Connor, M., Roth, G.A., Sacco, R., Ezzati, M., Naghavi, M., Murray, C.J. and Feigin, V.L. (2014) The Global Burden of Hemorrhagic Stroke: A Summary of Findings from the GBD 2010 Study. Global Heart, 9 , 101-106. https://doi.org/10.1016/j.gheart.2014.01.003

[2] Stewart, J.A., Dundas, R., Howard, R.S., Rudd, A.G. and Wolfe, C.D.A. (1999) Ethnic Differences in Incidence of Stroke: Prospective Study with Stroke Register. BMJ, 318, 967. https://doi.org/10.1136/bmj.318.7189.967

[3] Alter, M. (1994) Black-White Differences in Stroke Frequency: Challenges for Research. Neuroepidemiology, 13, 301-307. https://doi.org/10.1159/000110395

[4] Sacco, R.L., Hauser, W.A., Mohr, J.P. and Foulkes, M.A. (1991) One-Year Outcome after Cerebral Infarction in Whites, Blacks, and Hispanics. Stroke, 22, 305-311. https://doi.org/10.1161/01.STR.22.3.305

[5] Bejot, Y., Rouaud, O., Benatru, I., Fromont, A., Couvreur, G., Caillier, M., Gentil, A., Osseby, G.V., Lemesle, M., Decavel, P., Medeiros, E., Moreau, T.H. and Giroud, M. (2008) Les apports du registre dijonnais des accidents vasculaires cérébraux en 20 ans d'activité [Contribution of the Dijon Stroke Registry after 20 Years of Data Collection]. Revue Neurologique, 164, 138-147. https://doi.org/10.1016/j.neurol.2007.06.003

[6] Smadja, D., Cabre, P., May, F., Fanon, J.L., Rene-Corail, P., Riocreux, C., Charpentier, J.C., Fournerie, P., Saint-Vil, M., Ketterlé, J. and ERMANCIA Study Group (2001) ERMANCIA: Epidemiology of Stroke in Martinique, French West Indies: 
Part I: Methodology, Incidence, and 30-Day Case Fatality Rate. Stroke, 32, 2741-2747. https://doi.org/10.1161/hs1201.099385

[7] Galanth, S., Tressieres, B., Lannuzel, A., Foucan, P. and Alecu, C. (2014) Factors Influencing Prognosis and Functionaloutcome one Year after a First-Time Stroke in a Caribbean Population. Archives of Physical Medicine and Rehabilitation, 95, 2134-2139. https://doi.org/10.1016/j.apmr.2014.07.394

[8] Brott, T., Adams, H.P., Olinger, C.P., Marler, J.R., Barsan, W.G., Biller, J., Spilker, J., Holleran, R., Eberle, R., Hertzberg, V., et al. (1989) Measurements of Acute Cerebralinfarction: A Clinical Examination Scale. Stroke, 20, 864-870. https://doi.org/10.1161/01.STR.20.7.864

[9] Rankin, J. (1957) Cerebralvascular Accidents in Patients over the Age of 60. Scottish Medical Journal, 2, 200-215.

[10] Bonita, R. and Beaglehole, R. (1988) Modification of Rankin Scale: Recovery of Motor Functionafter Stroke. Stroke, 9, 1497-1500. https://doi.org/10.1161/01.STR.19.12.1497

[11] Reinhold, S., Christian, E., Stefan, R., Helena, S. and Franz, F. (2003) Progression of Cerebral White Matterlesions: 6-Year Results of the Austrian Stroke Prevention Study. The Lancet, 361, 2046-2048. https://doi.org/10.1016/S0140-6736(03)13616-1

[12] Hill, M.D. and Muir, K.W. (2013) INTERACT-2: Should Blood Pressure Be Aggressively Lowered Acutely after Intracerebral Hemorrhage? Stroke, 44, 2951-2952. https://doi.org/10.1161/STROKEAHA.113.002790

[13] Sturgeon, J.D., Folsom, A.R., Longstreth, W.T., Shahar, E., Rosamond, W.D. and Cushman, M. (2007) Risk Factors for Intracerebral Hemorrhage in a Pooled Prospective Study. Stroke, 38, 2718-2725.

https://doi.org/10.1161/STROKEAHA.107.487090

[14] Lannuzel, A., Salmon, V., Mével, G., Malpote, E., Rabier, R. and Caparros-Lefebvre, D. (1999) Epidémiologie des accidents vasculaires cérébraux en Guadeloupe et rôle du trait drépanocytaire. Revista de Neurología (Paris), 155, 351-356. 